\title{
O desafio francês: a nova legislação sobre a reforma do ensino superior e da pesquisa na França e sua complexidade
}

The French challenge: the new law on the reform of higher education and research in France and its complexity

Le defi français: la nouvelle legislation sur la reforme de l'enseignement superieur et de la recherche en france et sa complexité

\section{Leda Rouquayrol Guillemette*}

\section{Resumo}

O agente desencadeador deste artigo foi o lançamento do debate sobre a Lei da Reforma Universitária (LRU) elaborada e aplicada em todo o território francês pelo Governo Sarkozy desde 2007. A atual realidade da complexa estrutura francesa de ensino e pesquisa, verdadeiro desafio no âmbito da competição internacional, é desconhecida pela maior parte das instituições brasileiras. Esta contribuição tem como objetivo trazer à luz os meandros da reforma do ensino superior na França e sua complexidade, contribuindo, assim, com o processo de mobilidade e integração dos pesquisadores brasileiros nos programas franceses.

Palavras-chave: Lei da Reforma Universitária - LRU. Ensino francês. Reforma. Globalização. Cooperação internacional.

* Doutora em Civilização, diplomada pela Universidade Paris IX-Dauphine em Estudos Políticos. Mestre em Direito pela Faculdade de Direito da Universidade Federal do Ceará. Curso de Especialização em Direito pela Faculdade de Direito da Universidade Federal do Ceará. Professora titular da Faculdade de Relações Internacionais da Universidade do Havre, desde 1989, onde criou o Master de Comércio com a América Latina. Coordenadora da mobilidade de estudantes e professores entre Le Havre e Fortaleza, no âmbito de um convênio universitário bilateral. Fortaleza - CE - Brasil. E-mail: leda.guillemette@univ-lehavre.fr 


\section{Abstract}

The causative agent of this article was the launch in France of the debate about the university reform law (LRU) designed and implemented in France during Sarkozy Government since 2007. The current reality of the complex structure of teaching and research in France, the real challenge for the international competition, is largely unknown by Brazilian institutions. This modest contribution aims to bring to light the intricacies of higher education reform in France and its complexity, contributing in the mobility and integration of Brazilian researchers to French educational programs.

Keywords: University Reform Law - LRU. French education. Reform. Globalization. International cooperation.

\section{Résumé}

L'idée de cet article est née avec la mise en route en France du débat sur la loi de la réforme universitaire - LRU élaborée et mise en place en France par le Gouvernement Sarkozy à partir de 2007. L'actuelle réalité concernant la structure complexe de l'enseignement et de la recherche en France, véritable défi dans le cadre de la compétition internationale, est méconnue par la plupart des institutions brésiliennes. Cette modeste contribution a pour objectif la mise en lumière des méandres de la réforme de l'enseignement supérieur en France et sa complexité, apportant ainsi une contribution au processus de mobilité et d'inclusion de chercheurs brésiliens aux programmes français.

Mots-clés: Loi de Réforme Universitaire - LRU. Enseignement français. Réforme. Mondialisation. Coopération internationale.

\section{Introdução}

O presente artigo trata da Lei da Reforma Universitária (LRU) do Governo Sarkozy, de 2007, que foi discutida pelos legisladores em sessões parlamentares acaloradas na França. A atual estrutura do ensino e da pesquisa naquele país é extremamente complexa, um verdadeiro desafio no âmbito da competição internacional. Merece reflexão o impacto da globalização neste setor nos últimos anos, levando 
o governo francês a legislar com a finalidade de reformar e modernizar o sistema, implantando a autonomia das universidades, assim como os Polos de Ensino Superior e Pesquisa (PRES), ou Plateau Saclay, entre outras importantes modificações que alteraram a face do ensino e da pesquisa na França. Atualmente ${ }^{1}$, um projeto de lei do governo socialista está sendo debatido por parlamentares e sindicados com o intuito de modificar a LRU de 2007.

Quando do lançamento na França do programa brasileiro "Ciência sem Fronteiras" para os estudantes da graduação candidatos a uma bolsa de estudos no exterior, ficou patente o pouco conhecimento sobre a realidade francesa do sistema institucional e administrativo de ensino e pesquisa. O objetivo geral deste artigo é levar ao público especializado uma contribuição que oriente as ações e decisões da cooperação educacional em nível superior, por meio da difusão de informações aos órgãos de fomento à pesquisa e ao estudo acadêmico nos âmbitos federal, regional e das instituições de ensino brasileiras relacionadas às atividades acadêmicas na França.

Em dezembro de 2011, a CAPES e o CNPq lançaram, no Brasil, um edital do Programa Ciências sem Fronteiras (CsF) para o financiamento de 10.000 bolsas de estudos, entre 2012 e 2015, na França. Nesse programa, a CAPES e o CNPq, em colaboração com a embaixada da França em Brasília, selecionam estudantes do setor de ciências exatas nos níveis de $2^{\circ}, 3^{\circ}$ e $4^{\circ}$ anos de estudos (correspondendo ao L2, L3 e M1 na França). Os candidatos são selecionados pela CAPES segundo os critérios de excelência acadêmica e linguística, com prioridade para os $10 \%$ melhores estudantes de cada universidade.

Do lado francês, é a Agência CampusFrance que está encarregada da gestão, localização e acompanhamento dos bolsistas do Programa CsF. Ela criou um programa informático capaz de administrar e fornecer informações. Cada instituição de ensino superior que deseje acolher

${ }^{1}$ Até dezembro de 2012 a nova lei ainda se encontrava em discussão. 
os estudantes brasileiros deve aceitar as regras estabelecidas pela CampusFrance, sendo então habilitada a conectar-se e selecionar os estudantes em função de sua instituição de origem, seu nível de estudos e linguístico (B1 ou B2).

Considerando a decisão do Governo da Presidente Dilma Rousseff de internacionalizar o ensino e a pesquisa, é deveras importante que as instituições brasileiras de ensino superior possam ter acesso fácil a uma informação completa e simples, sob a forma de um artigo, contendo os meandros da organização do ensino e da pesquisa na França. Essa informação pode ser valiosa dentro do processo de integração dos pesquisadores brasileiros aos programas internacionais de mobilidade.

O conteúdo do presente trabalho foi redigido de maneira a dar ao leitor uma visão próxima da realidade francesa atual, levando em conta a reforma implantada pela LRU de 2007. São apresentados os tipos de instituições de ensino superior existentes na França (universidades, escolas de ensino superior, academias etc.), a maneira como são feitas atualmente suas organizações e as posições das principais delas, de acordo com vários rankings nacionais e internacionais.

\section{A presença do Estado no ensino superior público francês}

No preâmbulo da Constituição francesa de 1946 (alínea 13) está previsto que "a organização do ensino público, gratuito e laico em todos os níveis é um dever do Estado". Por outro lado, "o Estado define por lei os princípios fundamentais do ensino e organiza o ensino público em todos os níveis" (Art. 34 da Constituição de 4 outubro de 1958).

O serviço público de ensino é dirigido pelos Ministros da Educação Nacional (MEN) e do Ensino Superior e da Pesquisa (MESR):

Estes dois Ministros preparam e implementam a política do Governo no que concerne o acesso de cada indivíduo ao saber, assim como o desenvolvimento e a avaliação de conhecimentos no ensino pré-elementar, elementar, secundário e superior. (FRANCE, 2000; FRANCE, 2007). 
Para elaborar e colocar em execução suas políticas, os ministros contam com a assistência de um conjunto de direções, serviços e escritórios que constituem as Administrações Centrais dos Ministérios.

A França está dividida em zonas acadêmicas (circonscriptions). Cada Academia é administrada por um reitor ${ }^{2}$, que é nomeado por decreto pelo Presidente da República no Conselho de Ministros. O reitor, responsável pela totalidade do sistema educativo da Academia sob sua tutela (escolas maternais, escolas primárias, colégios, liceus, universidades e Grandes Escolas), representa o MEN e o MESR e aplica as diretrizes ministeriais. Cabe a ele definir uma política de educação e formação no âmbito das orientações nacionais e manter relações com os responsáveis políticos e socioeconômicos da Academia e da Região. A Região é uma coletividade territorial em número de 22 na França Metropolitana. Uma Região pode ter várias Academias.

O reitor da Academia também é o chanceler das universidades. Ele dirige a Chancelaria, estabelecimento público com caráter administrativo que assegura a administração de bens e encargos indivisos entre vários estabelecimentos de ensino superior, conforme estabelecem os artigos L.222-1 e L.222-2 do Código da Educação.

Como chanceler das universidades, o reitor da Academia assiste ou é representado nas reuniões do Conselho de Administração dos estabelecimentos públicos que possuam caráter científico, cultural e profissional. Ele recebe, em tempo hábil, comunicação das deliberações e decisões dos reitores de universidades ou de diretores (artigo L.711-8 do Código da Educação). O público em geral tem acesso ao relatório anual estabelecido pelo reitor sobre o exercício do controle da legalidade das decisões e deliberações dos órgãos estatutários de estabelecimentos públicos com caráter científico, cultural e profissional (artigo L.711-8 do Código da Educação).

Na França, o termo "reitor" significa o responsável por toda a rede de ensino na Academia sob sua tutela. Não confundir com o termo utilizado no Brasil, indicando o cargo ocupado pelo responsável por uma universidade. Na França, o termo usado para este cargo é "presidente". 


\subsection{As evoluções recentes}

Em 1988, o então ministro encarregado da educação nacional decidiu levar $80 \%$ de um grupo etário até o baccalauréat (diploma de fim de estudos secundários) com sucesso, quando a taxa, na época, era de $35 \%$. Após essa decisão, a França ofereceu aos jovens franceses um acesso amplo ao ensino superior. Em 2008, isso implicava em 78,2\% de bacheliers, ou seja, jovens com sucesso no ensino secundário, prontos para integrar o ensino superior, no entanto, nem sempre apresentando um nível de preparo suficiente (CHABBAL; GOULARD, 2007).

Essa nova realidade obrigou a uma adaptação do sistema de ensino superior às necessidades de uma população cada vez mais numerosa, que foi acolhida principalmente nas carreiras clássicas das universidades e das escolas de engenharia, ainda que em menor número nestas. O número de classes preparatórias também aumentou durante esse período. As universidades tiveram que adaptar-se às necessidades da sociedade francesa e desenvolveram formações profissionalizantes, com licenças profissionais e diplomas de ensino superior especializado (hoje chamados de master profissionais). A prática de estágios de alguns meses em empresas, os quais existiam somente nas Grandes Escolas, foi generalizada. Consequentemente, foi necessário aumentar a capacidade de absorção dos bacheliers nos estabelecimentos de ensino superior. O número de bolsas ofertadas por critérios sociais também foi aumentado, o que representou um alto custo para toda a sociedade (LEFEBVRE, 2010).

$\mathrm{Na}$ continuidade da Declaração da Sorbonne (1998) e da Declaração de Bolonha (1999), com vistas a criar um espaço europeu do ensino superior, a França mudou a estrutura do seu sistema e de suas formações universitárias ${ }^{3}$. Em 1999, com a assinatura dos acordos de Bolonha, os governos europeus, associando alguns países vizinhos,

O Processo de Bolonha tem como objetivo a construção de uma Europa do saber com um modelo e objetivos comuns aos vários países aderentes. 
como a Rússia e a Turquia, decidiram harmonizar o ensino europeu para dar-lhe mais visibilidade e responder às crescentes demandas de mobilidade intraeuropeias, devido à integração econômica dos países da região. Os percursos no ensino superior foram uniformizados e os diplomas europeus de referência foram definidos: licença em 3 anos, master em 5 anos e doutorado em 8 anos. Os diplomas das escolas de engenharia foram assimilados aos master. Assim, a harmonização é uma realidade na Europa atual.

Para que a harmonização do ensino superior pudesse funcionar, organizou-se um sistema de transferência de créditos universitários (ECTS $)^{4}$. Os programas de mobilidade dentro da Europa em nível de master e doutorado foram reforçados com bolsas que permitem aos estudantes pagarem o custo suplementar provocado por uma estadia no exterior.

Os créditos ECTS apresentam três características. Eles são:

a) capitalizáveis: toda equivalência de Unidades de Ensino (UE) leva à aquisição definitiva dos créditos correspondentes;

b) transferíveis: sob aceitação da equipe pedagógica, podem ser transferíveis de um percurso de formação a outro, de um estabelecimento a outro, e permitem a validação de períodos de estudo no exterior ou em outra universidade francesa;

c) compensáveis: são obtidos pela aquisição de cada UE ou pela compensação das UE de um mesmo semestre (com base na média geral das notas obtidas na UE, ponderadas por coeficientes).

4 Os créditos ECTS são utilizados em todos os países da União Europeia, a fim de validar a aquisição das Unidades de Ensino (UE). Cada UE tem um valor definido pelo estabelecimento em créditos ECTS, que leva em conta o trabalho e a assiduidade do estudante. Com o objetivo de se permitir uma maior mobilidade europeia, uma referência comum foi fixada, correspondendo à aquisição de 180 créditos ECTS para o nível Licença e de 120 créditos suplementares para o nível Master. Um semestre de estudos equivale a 30 créditos. 
Em 2008, 12\% dos estudantes presentes na França eram estrangeiros e, dentre eles, $7 \%$ eram beneficiados por uma bolsa do governo francês. É interessante ressaltar que programas do tipo Erasmus financiam uma parte dos estudos dos franceses no exterior, inclusive fora da União Europeia, através do programa ampliado Erasmus Mundus (L'EUROPE, 2012).

Com a harmonização europeia, alguns diplomas franceses, como o Brevet de Técnico Superior (BTS) e o Diploma Universitário de Tecnologia (DUT), não tiveram seus correspondentes em nível de estudos curtos (2 anos). A fim de sanar o problema, foram criadas possibilidades para se completar os estudos, com a obtenção de uma licença e, eventualmente, um master.

Os estabelecimentos particulares de ensino superior se beneficiaram com uma autonomia de gestão e de escolha estratégica. No contexto do processo de Bolonha, a França decidiu ampliar essa autonomia a todos os estabelecimentos de ensino superior.

A reforma do ensino superior francês iniciada em 2007 dotou as universidades de uma capacidade comparável aos estabelecimentos privados. Em 2010, 60\% das universidades francesas já adotavam o estatuto, ganhando autonomia de gestão (BALME et al., 2012). Isso contribuiu para uma maior flexibilidade, sobretudo nas relações e intercâmbios internacionais. A harmonização do funcionamento dos diferentes tipos de estabelecimentos permitiu que eles se reagrupassem em estruturas regionais - os Polos Regionais de Ensino Superior (PRES) - ou se fundissem, criando entidades com maior visibilidade internacional.

\section{Comentários sobre a Lei da Reforma Universitária - LRU de 2007}

A Lei da Reforma Universitária de 2007 deu continuidade aos objetivos da Lei Orgânica de Finanças - votada em agosto de 2001 e aplicada em todos os níveis administrativos desde 2006 -, cujo 
objetivo era a modernização da gestão do Estado, com obrigação de transparência, informação financeira e certificação das contas das universidades por um commissaire aux comptes ${ }^{5}$.

As universidades estabelecem, em caráter plurianual, um contrato com o Estado francês que prevê dotações orçamentárias destinadas a cobrir despesas com funcionários, custeio e investimentos. As instituições devem, por sua vez, comprovar que as dotações são compatíveis com seus orçamentos anuais. Um decreto de aplicação da lei (junho de 2008) mantém o princípio de um debate no Conselho de Administração das universidades sobre as orientações gerais do orçamento do exercício, assim como as promessas de pagamento plurianuais planejadas.

Conforme a lei, a autonomia das universidades se dá em várias etapas. Primeiro, a Inspection Générale de l'Administration de L'Education Nationale et de la Recherche (Inspeção Geral da Administração da Educação Nacional e da Pesquisa) faz uma auditoria na universidade. Em seguida, a Agência de Mutualização das Universidades e Estabelecimentos ajuda a consolidar seus instrumentos de gestão interna e a assegurar suas obrigações em termos de gestão financeira e contábil, gestão de recursos humanos, da escolaridade e dos estudantes.

Desde 2009, o sistema de repartição dos meios segundo o desempenho distribui os meios fixados pela lei de finanças em função da atividade (número de estudantes presentes aos exames de licenças e master, número de professores/pesquisadores que publicam) e do desempenho dos estabelecimentos que se baseiam, sobretudo, na avaliação de formações efetuadas pela Agence d'Evaluation de la Recherche et de L'Enseignement Supérieur (Agência de Avaliação da Pesquisa e do Ensino Superior - AERES), no êxito da licença e no número de diplomados master. O Projeto de Lei de Finanças de

\footnotetext{
5 O comissaire aux comptes equivaleria no Brasil a um auditor fiscal responsável pela análise das contas públicas da instituição.
} 
2010 previa a atribuição de $20 \%$ de créditos baseado em critérios de desempenho e $80 \%$ em critérios relativos a atividades.

O financiamento das universidades é feito quase exclusivamente pelo Estado, mesmo que existam outras fontes, como o feito pelas coletividades territoriais, a arrecadação com as taxas de matrículas pagas pelas famílias e as empresas que financiam a formação contínua e a taxa de aprendizagem.

Mas a lei de 2007 também previu dar às universidades os meios de reforçar seus fundos, permitindo-Ihes fazer prospecção para o financiamento junto a parceiros públicos e privados. Ela permite doações feitas por particulares ou empresas sem o procedimento do acordo prévio dos Ministérios do Orçamento e do Ensino Superior. Dois tipos de fundações foram criadas: as universitárias e as fundações em parcerias.

ALRU transfere às universidades a gestão de um orçamento global que integra a massa salarial. Se as somas dedicadas à massa salarial no seio da dotação anual do Estado são limitativas, a universidade pode decidir consagrar uma parte de seus recursos à contratação de funcionários por tempo limitado ou ilimitado para ocupar cargos técnicos, administrativos, de ensino e de pesquisa. É ela que administra a atribuição de indenizações e complementos salariais.

Quanto à questão do estatuto dos professores pesquisadores administrada até então pelo decreto de 1984 - o Conselho Constitucional, em julho de 2010, homologou o novo texto dispondo sobre o estatuto dos professores pesquisadores (decreto de 2009) e o modo de contratação. A norma legitima a criação de comitês de seleção (substituindo as comissões de especialistas), cuja metade dos membros, escolhidos pelo reitor em razão de sua competência, pertence a outras universidades, legitimando igualmente a repartição de tarefas dos professores entre ensino, pesquisa e outras missões que Ihes podem ser confiadas.

A LRU autoriza às universidades que fazem o pedido serem proprietárias de seus bens mobiliários e imobiliários. Essa transferência se faz gratuitamente e pode ser acompanhada de um convênio entre 
partes, visando assegurar o patrimônio depois de feita uma avaliação. A passagem de um "Estado proprietário" a "universidades proprietárias" constitui uma necessidade e uma oportunidade, mas, em 2010, somente $10 \%$ das universidades eram candidatas a serem proprietárias de seus bens.

Em 2010, 60\% das universidades optaram pelas responsabilidades e competências ampliadas (RCE) conferidas pela lei, significando a gestão da massa salarial, do orçamento e da estratégia do estabelecimento, com uma avaliação em matéria de pesquisa, de ensino e de inclusão profissional dos estudantes (BALME et al., 2012).

No entanto, mesmo com os esforços feitos na aplicação da LRU, subsistem interrogações sobre o futuro do serviço público de ensino superior, assim como sobre a finalidade e o papel da universidade. Com a criação dos novos encargos obrigatórios ou facultativos, o meio universitário mudou, mas alguns problemas estruturais continuam, tais como a gestão moderna das universidades, o concurso para a entrada nos cursos universitários e a diferença entre as Grandes Escolas Superiores e as universidades.

\section{As universidades}

Dois tipos de estabelecimento integram o ensino superior francês: as universidades e as Escolas (Grandes Escolas e Escolas Especializadas), estabelecimentos privados ou públicos acessíveis por concurso ${ }^{6}$.

O ensino universitário na França é assegurado a todos aqueles que obtêm o baccalauréat. Financiadas pelo Estado, 82 universidades públicas se encontram instaladas por todo o território francês e propõem àqueles que tiveram sucesso no ensino secundário tanto um percurso

\footnotetext{
6 A porcentagem do ensino particular na França ainda é pequena - inferior a 15\% (FRANCE, online).
} 
de estudos profissionalizantes curto, como também formações mais gerais e longas (FRANCE, on-line).

A maioria dos cursos oferecidos pelas universidades, sobretudo em ciências humanas e sociais, como é o caso do Direito e da Economia, não exige um concurso de ingresso. Por sua vez, para ter acesso aos cursos de Medicina, Odontologia e Farmácia, é necessário submeterse a uma seleção no fim do primeiro ano de faculdade (uma elevada porcentagem de estudantes não consegue passar no concurso no primeiro ano e acaba escolhendo outras carreiras). Para os diplomas de engenharia e as licenças profissionalizantes, o concurso é feito antes do primeiro ano. Para ingressar nas Grandes Escolas, é necessário fazer dois anos de preparação aos concursos, geralmente oferecida pelos liceus.

\subsection{A formação profissional}

O Diploma Universitário de Tecnologia (DUT) e o Brevet de Técnico Superior (BTS) são formações profissionalizantes que duram de dois a três anos. O DUT, que contém 25 especializações, advém dos cursos nos Institutos Universitários de Tecnologia (IUT), estabelecimentos de formação integrada à Universidade, enquanto a preparação do BTS ocorre nos liceus.

Depois de um diploma de BTS ou um de IUT, é possível preparar uma licença profissional em um ano, que tem como característica a colaboração entre a universidade e as empresas.

\subsection{A formação "geral"}

O ensino universitário francês se enquadra no esquema europeu de estudos superiores nascido com o Processo de Bolonha. Ele organiza a formação dos estudantes segundo três diplomas sucessivos: Licença, Master e Doutorado (LMD). Um determinado número de créditos é atribuído aos dois primeiros diplomas (European Credit Transfer System - ECTS) 


\subsection{Organização dos estudos}

A Licença é obtida com 6 semestres de estudos. O Master é obtido com 4 semestres de estudos. Existe uma diferença entre o Master de pesquisa e o Master profissional, pois este prepara o estudante para uma inserção direta no mundo do trabalho. O Doutorado, que demanda a redação de uma tese, é obtido com mais três anos de estudos.

\subsection{Universidades e Grandes Escolas}

A dualidade do sistema de ensino superior francês, no qual coabitam as universidades clássicas e um sistema de Grandes Escolas, é uma particularidade da França. Historicamente, as Grandes Escolas nasceram para dar profissionais eficientes ao país durante a Revolução Francesa. O sucesso dessa empreitada nos setores técnicos, do comércio e da ciência política abriu um espaço para as Grandes Escolas na cena universitária nacional.

As instituições universitárias eram fortemente associadas à Igreja e à Monarquia. Face aos desafios de mudanças rápidas no contexto de conflito com os países vizinhos, a França desenvolveu um sistema que já existia: as Escolas recebiam as elites através de concursos difíceis e transmitiam a elas um saber técnico eficiente e rapidamente assimilável. A Escola Politécnica transformou-se no modelo das Grandes Escolas no século XIX e esse modelo se estendeu às disciplinas não técnicas. As Grandes Escolas continuam assegurando um ensino eficiente, no entanto, são as universidades que oferecem a possibilidade de se aprofundar os conhecimentos, através da pesquisa.

\section{Os diferentes tipos de formação no ensino superior na França}

O ensino superior na França se faz dentro dos estabelecimentos universitários, mas também nas escolas superiores profissionais ou Grandes Escolas. Algumas formações são feitas nos liceus, sobretudo 
as chamadas comumente de prepas, uma formação de dois anos que prepara os estudantes para o concurso das Grandes Escolas. O ensino pode ser dividido da seguinte forma: estudo universitário clássico, escolas superiores profissionais, Grandes Escolas, classes preparatórias e estudos de curta duração.

O estudo universitário clássico corresponde ao estudo organizado em torno de um grupo coerente de disciplinas acadêmicas conduzindo aos diplomas universitários. Esses diplomas coroam os estudos feitos depois do baccalauréat: em 3 anos, a licença; em 5 anos, o master; e em 8 anos, o doutorado. Como já foi dito, a entrada na universidade exige apenas o diploma de baccalauréat, ainda que em alguns cursos seja feita uma seleção.

No setor médico, das artes, do trabalho social ou da comunicação, os diplomas de referência são preparados nas escolas superiores profissionais. É feita uma seleção complementar depois do baccalauréat, seja concurso ou exame de dossiê, para entrar nessas escolas.

Para as Grandes Escolas, a entrada é seletiva e o acesso àquelas de maior prestígio é muito difícil. Elas garantem aos estudantes uma excelente inserção profissional. A seleção para o acesso às Grandes Escolas é feita logo depois do baccalauréat, através de classificação dos curriculum vitae ou de concurso. Também há a opção por concurso dois anos depois do baccalauréat; nesse caso, a preparação é feita nos liceus. Os que realizam esses dois anos de curso preparatório têm excelente acompanhamento. Para fazer parte desses cursos, os estudantes são escolhidos minuciosamente e só os melhores dossiês são aceitos.

Já os estudos de curta duração nasceram para responder às necessidades das empresas. Os estudos com dois anos de duração foram generalizados. Esses percursos são seletivos e podem ser feitos nos liceus, que preparam o diploma de BTS. Podem ser feitos também, com um DUT, nas universidades nos IUT. 


\subsection{Estabelecimentos públicos ou particulares}

A maioria dos estabelecimentos franceses de ensino superior, sobretudo as 82 universidades, são estabelecimentos públicos, dependendo, em geral, do Ministério do Ensino Superior e da Pesquisa ou de outros Ministérios (a Escola Politécnica, por exemplo, depende do Ministério da Defesa e a Escola de Minas de Paris ou de Saint-Étienne dependem do Ministério da Indústria). Todos esses estabelecimentos públicos são obrigados a estabelecerem taxas de matrículas com preços módicos (para o período 2009-2010, a média foi de 171 euros para a licença, 231 para o master e 350 para o doutorado). A taxa de matrícula para as Grandes Escolas públicas variou em torno de 700 euros. Todos esses estabelecimentos de ensino público dão diplomas reconhecidos pelo Estado.

No entanto, entre os 3.500 estabelecimentos de ensino superior na França, existem também instituições particulares, que têm liberdade de escolher o montante das taxas e anuidades, mas devem levar em conta as diretrizes quanto ao conteúdo dos cursos ofertados, para que seus diplomas sejam devidamente reconhecidos pelo Estado. Uma parte das instituições privadas é católica, mas outras são laicas e de excelente nível, sobretudo as Escolas de Engenharia e as Escolas de Comércio e Gestão. Essas instituições particulares recebem 14\% dos estudantes inscritos no ensino superior e representam $30 \%$ do número total de estabelecimentos superiores. Em 2006, 58 (32 Escolas de Engenharia, 13 Escolas de Gestão e 13 estabelecimentos católicos) foram subvencionadas pelo ministério encarregado do ensino superior. As Câmaras de Comércio e Indústria das Regiões francesas apoiam financeiramente numerosos estabelecimentos (CYTERMANN, 2006; SÈVE, 2009).

\section{0 papel do poder público no ensino superior}

Não se pode pensar o ensino superior na França sem refletir acerca do papel do Estado na consecução desse direito. E nesse tocante sobressaem dois aspectos centrais: o princípio da igualdade de oportunidades e o financiamento público da educação. 
5.1 O princípio da igualdade de oportunidades

A igualdade de oportunidades é uma questão sensível na maneira pela qual a França concebe seu sistema de educação, que se estendeu a todo o tecido do ensino superior. Debate-se no país sobre o papel do sistema do ensino superior, o qual, segundo alguns, poderia contribuir para a "reprodução das elites", pois os filhos ocupariam na sociedade uma posição comparável à dos pais. No entanto, outro grupo pensa que o papel do ensino superior é justamente o de possibilitar a mobilidade social. Essa problemática foi levada em consideração pela sociedade francesa e seus responsáveis políticos, com a preocupação de dar a todos o acesso ao ensino superior de qualidade. Essa sempre foi uma prioridade dos sucessivos governos franceses.

\subsection{0 financiamento}

As despesas imputadas ao ensino superior correspondem a 1,3\% do produto interno bruto francês. Elas são arcadas pela coletividade, seja através do financiamento direto pelo Estado da massa salarial do ensino superior e parte da atividade de pesquisa, seja pelas Regiões, que são responsáveis por parte dos projetos e do patrimônio imobiliário universitário, o que está mudando com a nova Lei de Responsabilidade Universitária - LRU (BALMER et al., 2012). Ou, ainda, através de deduções feitas às instituições de direito privado, como as Câmaras de Comércio e Indústria, quando financiam instituições de utilidade pública, como as Grandes Escolas de Comércio reconhecidas pelo Estado. Essa responsabilidade financeira do poder público permite, além da prática de taxas módicas de matrículas, uma política de ajuda total ou parcial aos estudantes durante os estudos.

\subsection{As bolsas e ajudas ao financiamento dos estudos}

$\mathrm{Na}$ França, o Estado, as coletividades públicas e as escolas assumem uma parte das despesas dos estudantes através de diversos dispositivos. 
a) Acesso às cidades universitárias: os alojamentos têm um aluguel a preço reduzido. São administrados pelo CROUS (Centre Régionaux des OEuvres Universitaires Sociales) e atribuídos prioritariamente aos estudantes cujas famílias dispõem de recursos modestos.

b) Ajudas personalizadas ao alojamento (APL): qualquer pessoa que resida na França e não ultrapasse certo teto de recursos financeiros recebe uma ajuda do Estado para pagar o alojamento principal. As Grandes Escolas (públicas e privadas) mantêm uma política de busca de alojamentos a preços moderados para seus estudantes. Os critérios sociais não são levados em consideração.

c) Bolsas por critério social: são atribuídas às famílias de acordo com os salários e outros critérios (número de filhos, distância entre a casa e o lugar de estudo, salários dos pais). As bolsas são atribuídas numa escala de 0 (gratuidade da taxa de matrícula) até 6 (460 euros mensais), segundo os recursos da família.

d) Empréstimos para estudantes: o Estado garante o empréstimo aos estudantes, com juros zero, de até 15.000 euros.

e) Bolsas por mérito: são atribuídas em determinadas condições, como complemento das bolsas por critério social. Levam em conta os resultados escolares ou universitários dos estudantes e podem corresponder a 200 euros mensais.

As escolas superiores particulares geralmente têm uma política de integrar as pessoas que têm recursos financeiros modestos. A Escola de Ciência Política de Paris, por exemplo, leva em conta a situação econômica da família do estudante no pagamento da taxa de matrícula e, em alguns casos, dá bolsas de estudos. HEC e ESSEC, Grandes Escolas de comércio, fazem redução de custos e dão bolsas aos estudantes que se enquadram nos critérios sociais do governo. Às 
vezes, os estudantes são dispensados de pagar os custos do curso, em parte ou completamente.

Em geral, os estudantes de $3^{\circ}$ ciclo se beneficiam de uma remuneração durante o trabalho de tese. Eles podem ser financiados pelo Estado, pela Região, por uma empresa ou por um emprego como professor no ensino secundário. O princípio segundo o qual um estudante que está fazendo tese deve receber uma ajuda financeira ficou estabelecido.

Alguns estudantes que preparam uma carreira de funcionário recebem remuneração durante a formação (escolas militares, escola politécnica, escolas normais superiores e escolas preparando a entrada na administração do Estado, geralmente acessíveis depois da Escola Politécnica ou Ciências Políticas, tais como Mines - Ministério da Indústria -, Ponts - Ministério do Equipamento - e ENA). Pode-se considerar que a entrada nessas Grandes Escolas prestigiosas é uma pré-seleção para as altas funções e cargos do Estado.

Em 2008-2009, 25\% dos 2.232.000 estudantes matriculados no ensino superior francês se beneficiaram de uma ajuda direta para os estudos. O acesso ao ensino superior universitário se democratizou (QUERE, 2011), no entanto, nota-se que a presença relativa de jovens originários de famílias modestas nos cursos mais seletivos e prestigiosos não aumenta e estaria inclusive em processo de regressão em comparação com as décadas passadas. Nas universidades, certo número de desafios deve ser enfrentado. No que concerne à quase gratuidade das taxas de matrícula, ela torna as universidades dependentes do Estado e das coletividades locais.

Quanto aos diplomas, verifica-se o número ainda pequeno de sucesso e aprovação nas formações generalistas. Com relação aos diplomas de master, que capacita os estudantes aos empregos mais interessantes e bem remunerados, eles só atingem uma minoria. Por fim, as formações de curta duração têm, em geral, uma taxa de inserção 
profissional satisfatória, mas conhecem problemas recorrentes quanto à mobilidade nacional e internacional.

\subsection{Custo e financiamento}

O custo anual médio de um estudante de nível secundário (collège) na França atinge 7.401 euros e aumentou em 33\% entre 1990 e 2004. O custo anual médio de um estudante de liceu (tês últimos anos do ensino secundário) é de 10.000 euros e as despesas aumentaram em $50 \%$ no mesmo período. No ensino primário, um aluno custa 4.217 euros por ano (4.128 euros no maternal). No nível do ensino superior, as universidades sofrem com um financiamento fraco em relação às suas necessidades (QUERE, 2011).

$\mathrm{Na}$ França, a taxa de matrícula dos estudantes universitários representa apenas $3 \%$ do orçamento total das universidades; o resto do orçamento é completado pelo Estado (FRANCE, on-line). Atualmente, o problema das universidades é encontrar novos financiamentos preservando o acesso ao nível superior ao maior número possível de cidadãos. Com efeito, um estudante fazendo parte das classes preparatórias (prepas) de acesso às Grandes Escolas custa 1,5 mais caro que um estudante de primeiro ciclo já matriculado na universidade. Cada vez mais, as Grandes Escolas são frequentadas quase exclusivamente pelas pessoas de estrato social superior.

\section{Os estabelecimentos públicos de ensino superior}

Os estabelecimentos públicos franceses de ensino superior constituem pessoas jurídicas de direito público encarregadas do serviço público de ensino superior. Eles têm um estatuto definido pelo livro VII do Código da Educação, que distingue:

- Os estabelecimentos públicos de caráter científico, cultural e profissional (EPSCP).

- Os estabelecimentos públicos de caráter administrativo (EPA). 
6.1 Os estabelecimentos públicos de caráter científico, cultural e profissional (EPSCP)

Estão aqui incluídos as universidades e os grandes estabelecimentos nacionais de ensino superior e de pesquisa, dispondo de autonomia administrativa, pedagógica, científica e financeira, assim como estatutária, no que diz respeito às universidades.

\section{Institutos nacionais politécnicos}

Institut National Polytechnique de Lorraine

Institut National Polytechnique de Toulouse

\section{Institutos e escolas fora das universidades}

\begin{tabular}{|l|l|}
\hline École Centrale de Lille & École Centrale de Lyon \\
\hline École Centrale de Nantes & Ecole Centrale de Marseille \\
\hline $\begin{array}{l}\text { Ecole Nationale Supérieure des Arts et } \\
\text { Industries Textiles }\end{array}$ & $\begin{array}{l}\text { Ecole Nationale Supérieure des Arts } \\
\text { et Industries de Strasbourg }\end{array}$ \\
\hline Institut de Physique du Globe de Paris & $\begin{array}{l}\text { Institut National des Sciences } \\
\text { Appliquées de Lyon }\end{array}$ \\
\hline $\begin{array}{l}\text { Institut National des Sciences Appliquées } \\
\text { de Rennes }\end{array}$ & $\begin{array}{l}\text { Institut National des Sciences } \\
\text { Appliquées de Toulouse }\end{array}$ \\
\hline $\begin{array}{l}\text { Institut National des Sciences Appliquées } \\
\text { de Rouen }\end{array}$ & $\begin{array}{l}\text { Institut National des Sciences } \\
\text { Appliquées de Strasbourg }\end{array}$ \\
\hline $\begin{array}{l}\text { Institut Supérieur des Matériaux et de la } \\
\text { Construction Mécanique }\end{array}$ & $\begin{array}{l}\text { Institut Supérieur de Mécanique de } \\
\text { Paris }\end{array}$ \\
\hline Université de Technologie de Compiègne & $\begin{array}{l}\text { Université de Technologie de Belfort- } \\
\text { Montbéliard }\end{array}$ \\
\hline Université de Technologie de Troye & - \\
\hline
\end{tabular}

\section{Grandes Estabelecimentos}

\begin{tabular}{|l|l|}
\hline Collège de France & $\begin{array}{l}\text { Conservatoire National des Arts et } \\
\text { Métiers (CNAM) }\end{array}$ \\
\hline École Centrale des Arts et Manufactures & $\begin{array}{l}\text { École des Hautes Études en Sciences } \\
\text { Sociales (E.H.E.S.S.) }\end{array}$ \\
\hline ECAM) & $\begin{array}{l}\text { École Nationale Supérieure d'Arts et } \\
\text { Métiers (ENSAM) }\end{array}$ \\
\hline
\end{tabular}




\begin{tabular}{|l|l|}
\hline $\begin{array}{l}\text { Ecole Nationale Supérieure des Sciences } \\
\text { de I'Information et des Bibliothèques } \\
\text { (ENSSIB) }\end{array}$ & $\begin{array}{l}\text { École Pratique des Hautes Études } \\
\text { (E.P.H.E.) }\end{array}$ \\
\hline $\begin{array}{l}\text { Institut d'Études Politiques de Paris } \\
\text { (I.E.P.) }\end{array}$ & $\begin{array}{l}\text { Institut National des Langues et } \\
\text { Civilisations Orientales (INALCO) }\end{array}$ \\
\hline Observatoire de Paris & $\begin{array}{l}\text { Muséum National d'Histoire Naturelle } \\
\text { (M.N.H.N) }\end{array}$ \\
\hline Palais de la Découverte & $\begin{array}{l}\text { Institut National d'Histoire de l'Art } \\
\text { (INHA) }\end{array}$ \\
\hline $\begin{array}{l}\text { Université de Technologie en Sciences } \\
\text { des Organisations et de la Décision de } \\
\text { Paris-Dauphine }\end{array}$ & $\begin{array}{l}\text { École des Hautes Études en Santé } \\
\text { Publique (E.H.E.S.P) }\end{array}$ \\
\hline $\begin{array}{l}\text { Institut National Polytechnique de } \\
\text { Bordeaux (IPB) }\end{array}$ & $\begin{array}{l}\text { Institut Polytechnique de Grenoble - } \\
\text { Groupe Grenoble INP }\end{array}$ \\
\hline
\end{tabular}

\section{Escolas francesas no exterior}

\begin{tabular}{|l|l|}
\hline Casa de Velázquez de Madrid & École Française Archéologie Athènes \\
\hline École Française d'Extrême-Orient & École Française de Rome \\
\hline $\begin{array}{l}\text { Institut Français d'Archéologie Orientale } \\
\text { du Caire }\end{array}$ & - \\
\hline
\end{tabular}

\section{Escolas normais superiores}

École Normale Supérieure de Paris ULM École Normale Supérieure de Cachan École Normale Supérieure de Lyon

\subsection{Academias e universidades}

Na França, existem 82 universidades públicas, financiadas pelo Estado, o qual, através de um procedimento rigoroso, habilita os diplomas que elas oferecem, o que permite um excelente nível de formação por um custo anual particularmente acessível.

As universidades recebem $80 \%$ dos estudantes, dos quais $10 \%$ são estrangeiros. Elas se encontram instaladas por todo o território francês e acolhem o essencial do desenvolvimento da pesquisa pública na França: o nível do ensino é reconhecido como elevado e os recentes 
prêmios Nobel franceses foram atribuídos às universidades (FRANCE, on-line).

A França programou uma "Estratégia nacional de pesquisa e inovação". Trata-se da definição das prioridades de pesquisa durante quatro anos, para ultrapassar com êxito os desafios do conhecimento, da tecnologia e da sociedade. Os três setores definidos para o período 2009/2012 são:

a) A saúde, a alimentação e as biotecnologias.

b) A urgência ambiental e as ecotecnologias.

c) A informação, a comunicação e as nanotecnologias.

Mais de 300 escolas doutorais, com 62.000 professores pesquisadores, asseguram a formação para a pesquisa, em estreita parceria com mais de 1.200 laboratórios de pesquisa (FRANCE, online).

As grades curriculares propostas pelas universidades encontramse mais abertas ao intercâmbio com o mundo profissional. $O$ estágio feito durante os estudos universitários é cada vez mais frequente para os estudantes em geral (30\%) e para os estudantes em Master $2(60 \%)^{7}$ (FRANCE, on-line).

As universidades organizaram um setor de ajuda ao estágio e outro de ajuda à inserção profissional, encarregados de divulgar juntos aos estudantes as propostas de estágio e emprego e ajudá-los a ter sucesso nessa empreitada.

\subsection{Estabelecimentos públicos com caráter administrativo (EPA)}

São os estabelecimentos com finalidade mais profissional e os estabelecimentos de documentação. Seus decretos de criação estabelecem um estatuto diferenciado. Organizam-se da seguinte forma:

\footnotetext{
${ }^{7}$ O Master 2 equivale à conclusão de dois anos de estudo após a conclusão da licence.
} 
15 Escolas Nacionais Superiores de Engenharia, 8 Instituts d'Études Politiques de Province e 10 EPA autônomos. Dentre esses, podem-se citar as seguintes instituições:

\section{Escolas com habilitação para diplomar engenheiros}

\begin{tabular}{|l|l|}
\hline $\begin{array}{l}\text { École Nationale Supérieure de } \\
\text { l'Électronique et de ses Applications de } \\
\text { Cergy (ENSEA) }\end{array}$ & $\begin{array}{l}\text { Institut Français de Mécanique } \\
\text { Avancée (IFMA) }\end{array}$ \\
\hline $\begin{array}{l}\text { École Nationale d'Ingénieurs (ENI) de } \\
\text { Saint-Étienne }\end{array}$ & $\begin{array}{l}\text { École Nationale Supérieure de } \\
\text { la Nature et du Paysage de Blois } \\
\text { (ENSPB) }\end{array}$ \\
\hline
\end{tabular}

\section{Outros estabelecimentos}

\begin{tabular}{|c|c|}
\hline $\begin{array}{l}\text { École Nationale Supérieure des Arts et } \\
\text { Techniques du Théâtre (ENSATT) }\end{array}$ & $\begin{array}{l}\text { École Nationale Supérieure Louis } \\
\text { Lumière (ENSLL) }\end{array}$ \\
\hline Observatoire de la Côte d'Azur (OCA) & $\begin{array}{l}\text { Centre Universitaire de Formation } \\
\text { et de Recherche Jean-François- } \\
\text { Champollion (CUFR Jean-François- } \\
\text { Champollion) }\end{array}$ \\
\hline $\begin{array}{l}\text { Centre Universitaire de Formation et de } \\
\text { Recherche de Nîmes (CUFR de Nîmes) }\end{array}$ & $\begin{array}{l}\text { Institut National Supérieur de } \\
\text { Formation et de Recherche pour } \\
\text { l'Éducation des Jeunes Handicapés et } \\
\text { les Enseignements Adaptés }\end{array}$ \\
\hline
\end{tabular}

\subsection{Outros estabelecimentos públicos}

Essa diversidade estatutária não cobre os diferentes tipos de formação. As formações de engenharia podem ser feitas numa faculdade de uma universidade (uma escola politécnica universitária); em um estabelecimento público de caráter científico, cultural e profissional EPSCP (uma Escola Central); e em estabelecimentos públicos com caráter administrativo - E.P.A. (Escolas Nacionais Superiores de Engenheiros), ligados ou não a um EPSCP ou tendo um estatuto de estabelecimento privado. 


\section{As escolas de engenharia}

Depois do decreto de 13 de abril de 2006, cada uma das 227 escolas de engenharia que reconhecem o título de engenheiro diplomado pela Comissão de Títulos de Engenharia tem a possibilidade de ser membro da Conferência dos Diretores de Escolas Francesas de Engenharia (CDEFI), uma instância que age em nome de todas as escolas francesas de engenharia. Cada uma delas pode se beneficiar com os serviços ofertados pela Conferência.

\subsection{Multiplicidade de escolas e estatutos jurídicos}

Dois estatutos jurídicos coexistem atualmente:

- As escolas públicas de engenharia controladas pelo governo através dos ministérios e organizadas, seja independentemente das universidades ou com elas (escolas que existem dentro das universidades).

- As escolas particulares de engenharia controladas, por exemplo, pelas Câmaras de Comércio e Indústria $(\mathrm{CCl})$.

Numerosas escolas mantêm laços fortes de colaboração com as universidades, sobretudo no campo da pesquisa. As escolas de engenharia ou são generalistas ou muito especializadas. Todos os domínios científicos estão representados: química, física, automação, aeronáutica, eletrônica etc.

O conjunto desses estabelecimentos constitui uma importante rede presente em todo o território francês, formando engenheiros em todas as disciplinas e domínios de ciências de engenharia (mais de 60.000 estudantes de engenharia inscritos em 2008). Além do ensino, esses estabelecimentos fazem pesquisa e transferência tecnológica.

\subsection{Escolas organizadas em redes}

Numerosas escolas organizam-se em redes e interagem entre si de modo variável. Entre as redes mais citadas, estão: 


\begin{tabular}{|l|l|}
\hline $\begin{array}{l}\text { Arts \& Métiers ParisTech: École Nationale } \\
\text { Supérieure d'Arts et Métiers }\end{array}$ & EC Groupe des Écoles Central \\
\hline ENI: Écoles Nationales d'Ingénieurs & $\begin{array}{l}\text { FESIC: Fédération d'Écoles } \\
\text { Supérieures d'Ingénieurs et de } \\
\text { Cadres }\end{array}$ \\
\hline $\begin{array}{l}\text { FGL: Fédération Gay-Lussac Regroupant } \\
\text { des Écoles de Chimie }\end{array}$ & $\begin{array}{l}\text { GEA: Groupe des Écoles } \\
\text { Aéronautiques et Spatiales }\end{array}$ \\
\hline $\begin{array}{l}\text { GEIPI: Groupement d'Écoles d'Ingénieurs } \\
\text { Publiques à Parcours Intégré }\end{array}$ & GEM: Groupe des Écoles des Mines \\
\hline $\begin{array}{l}\text { INP: Instituts Nationaux Polytechniques } \\
\text { (3 réseaux: INP Lorraine, INP Toulouse et } \\
\text { Grenoble INP) }\end{array}$ & $\begin{array}{l}\text { INSA: Instituts Nationaux des } \\
\text { Sciences Appliquées }\end{array}$ \\
\hline Institut TELECOM & $\begin{array}{l}\text { POLYTECH: Réseau National des } \\
\text { Écoles d'Ingénieurs Polytechniques } \\
\text { des Universités }\end{array}$ \\
\hline $\begin{array}{l}\text { Union des Grandes Ecoles Indépendantes } \\
\text { (UGEI) }\end{array}$ & UT: Universités de Technologie \\
\hline
\end{tabular}

\section{Classificação nacional das universidades francesas em ciências, tecnologia e saúde, segundo a taxa de inserção profissional}

O Ministério do Ensino Superior e da Pesquisa (MESR) francês estabeleceu uma classificação por universidade, por domínio de estudos e por disciplina. São critérios que diferem totalmente da classificação internacional, como a de Xangai. O MESR posiciona as universidades da França numa lista em que aparecem, nos primeiros lugares, universidades totalmente ausentes nas classificações internacionais. Esse estudo inédito, realizado entre dezembro de 2009 e julho de 2010, versa sobre os titulares de diploma de master obtido em 2007, formados nas universidades francesas. Por meio de questionários, avaliou-se a situação profissional dos titulares do diploma 30 meses depois da obtenção deste. A taxa de respostas foi de 64\% (BALME, 2012). 
8.1 A classificação acadêmica internacional das universidades

A classificação acadêmica das universidades (Academic Ranking of World Universities) é uma classificação das principais universidades do mundo, estabelecida pelos pesquisadores da Universidade Jiao-Tong de Xangai, na China. A cada ano essa classificação propõe uma lista das 500 melhores universidades mundiais, através de uma metodologia essencialmente baseada na qualidade da pesquisa (QUE VALENT, 2006).

A classificação de Xangai para 2012 continua estável no que diz respeito à posição das universidades francesas, praticamente ausentes nos 100 primeiros lugares, colocando os estabelecimentos americanos nos primeiros lugares.

Das 500 melhores universidades, somente 20 são francesas, contra 150 americanas, 42 chinesas e 38 britânicas. A primeira universidade francesa da lista, Université de Paris-Sud, fica em $37^{\circ}$ lugar. As próximas na lista são a Université Pierre-et-Marie-Curie, que perdeu 1 ponto e ficou em $42^{\circ}$ lugar, e a École Normale Supérieure, que perdeu 4 pontos, classificando-se em $73^{\circ}$ lugar (QUE VALENT, 2006). As universidades americanas conseguiram os 17 primeiros lugares das 20 melhores universidades, as mesmas de 2011, dentre elas, Harvard, Standford, Massachusetts Institute of Technology (MIT) e Berkeley (QUE VALENT, 2006).

Divulgada desde 2003, a classificação mundial é sempre esperada com certa apreensão na França, pois suas universidades não estão ocupando as melhores posições. Os critérios utilizados na classificação de Xangai são: desempenho em matéria de pesquisa, número de prêmios Nobel, de medalhas Fields e de artigos publicados unicamente em revistas de língua inglesa. Aparentemente, a França leva desvantagem com a organização de seu ensino superior, às vezes incompreensível para quem vê de fora, com divisões entre universidades, Grandes Escolas e institutos de pesquisa. Além disso, os critérios de classificação levam claramente em conta os aspectos de pesquisa, bem mais do que os de ensino (BALME, 2012). 


\section{Os trunfos do sistema de ensino superior na França}

Apesar das dificuldades nas avaliações internacionais, o ensino superior francês e sua pesquisa científica possuem aspectos de grande destaque, como se verá a seguir.

\subsection{Os polos de pesquisa e de ensino superior (PRES)}

Os polos de pesquisa e de ensino superior (PRES) têm o estatuto de estabelecimento público de cooperação científica (EPCS), que é o instrumento mais adaptado para se articular formação e pesquisa, sobretudo sendo o EPCS o único a conceder ao PRES a possibilidade da emissão de diplomas.

Os PRES permitem que universidades, Grandes Escolas e organismos de pesquisa se engajem de maneira coerente, utilizando conjuntamente suas atividades e meios financeiros com o objetivo de propor uma oferta de pesquisa e de formação mais visível ao exterior e mais adaptada às necessidades do território francês.

Eles foram criados em 2006 pela Lei de Orientação de Programa e de Pesquisa. O desenvolvimento dos PRES acompanha naturalmente o acesso progressivo das universidades francesas a uma maior autonomia. Nesses polos, encontra-se o conjunto dos participantes do ensino superior e da pesquisa que trabalham juntos e unem suas forças e sua diversidade a serviço de projetos comuns.

Segundo os dados do MESR (FRANCE, on-line), a França contava com 23 PRES em maio de 2012. Eles são constituídos por quase 60 universidades e numerosos estabelecimentos, como escolas de engenharia, IEP, escolas de comércio, institutos nacionais politécnicos, grandes estabelecimentos (ENSAM, Institut de Physique de Grenoble, Institut de Physique du Globe de Paris etc.) e centros hospitalares.

É interessante verificar, através da lista dos 23 polos de pesquisa e de ensino superior, que eles se encontram em praticamente todo o território francês. 


\begin{tabular}{|l|l|}
\hline Universidade de Bordeaux & $\begin{array}{l}\text { PRES Bourgogne Franche-Comté } \\
\text { (ESTH - } \\
\text { Inovação Universidade) }\end{array}$ \\
\hline Universidade Europeia da Bretagne & Centre - Val de Loire Universidade \\
\hline Clermont Universidade & Universidade de Grenoble \\
\hline $\begin{array}{l}\text { HESAM (Hautes Études-Sorbonne-Arts } \\
\text { et Métiers) }\end{array}$ & Universidade Lille Nord de France \\
\hline PRES Limousin Poitou-Charentes & PRES da Universidade de Lorraine \\
\hline Universidade de Lyon & Universidade Montpellier Sud de France \\
\hline Universidade Nantes Angers Le Mans & Universidade de Toulouse \\
\hline $\begin{array}{l}\text { ParisTech (Institut des Sciences et } \\
\text { Technologies de Paris) }\end{array}$ & Sorbonne Paris Cité \\
\hline Universidade Paris Est & Paris Sciences et Lettres - Quartier latin \\
\hline Sorbonne Universidade & UniverSud Paris \\
\hline Normandia Universidade & Universidade Paris Grand Ouest \\
\hline $\begin{array}{l}\text { UFECAP(Universidade Federal Europeia } \\
\text { Champagne- Ardenne Picardie) }\end{array}$ & - \\
\hline
\end{tabular}

Os PRES foram concebidos como um instrumento de promoção dos estabelecimentos membros. É uma maneira pela qual a França tenta garantir um posicionamento melhor na competição científica internacional. O campo de competências dos estabelecimentos foi considerado um critério essencial da qualidade do PRES - os membros fundadores dos PRES escolheram a opção de uma delegação de competências em setores importantes, sobretudo em termos de pesquisa, formação doutoral e internacionalização.

Em termos de formação (doutorado, master), a coordenação dos estudos pelos polos possibilitará a emissão de diplomas com a chancela PRES correspondente às formações ofertadas por uma ou mais escolas ou universidades membros. No campo da pesquisa, todas as publicações científicas dos polos serão apresentadas sob uma assinatura única, o que poderá melhorar a visibilidade internacional das produções científicas dos membros de cada um. A transferência de determinadas competências ao PRES foi acompanhada por uma disponibilização de recursos financeiros e humanos originários dos estabelecimentos fundadores de cada polo. 
Os PRES constituem o meio mais eficiente e adaptado para organizar uma aproximação entre os estabelecimentos de uma mesma cidade ou região. Essa estrutura é suficientemente flexível para permitir uma fusão entre estabelecimentos, ou seja, um polo dando origem a um estabelecimento público com caráter científico, cultural e profissional. Ou, de modo mais simples, a criação de um PRES de cooperação entre estabelecimentos de ensino e pesquisa.

\subsection{O Plateau de Saclay}

Um decreto de 3 de março de 2009 classificou o Plateau de Saclay como projeto de interesse nacional, submetido ao artigo L.121-1 do Código de Urbanismo, ao qual se aplica um regime jurídico particular em razão de sua importância. O Estado francês é o responsável pela política urbana nessa área de 7.700 ha, dando ou não autorizações de ocupação de solo e de construção urbana.

Um projeto ambicioso e de grandes dimensões anima os debates na França. "A Grande Paris" é um projeto urbano, social e econômico que objetiva unir grandes territórios estratégicos da região francesa llede-France. Na realidade, o desenvolvimento dessa região chamada Plateau de Saclay é de interesse nacional, pois visa o desenvolvimento e a redinamização econômica da região parisiense. Trata-se da instalação de polos de atividades científicas e tecnológicas a fim de se criar um setor com perspectivas diferenciadas, capazes de esquentar a economia francesa. Será um desafio e tanto, pois se trata de congregar as forças das escolas, dos polos de pesquisa e das empresas para que a região parisiense seja transformada num atrativo para a cena científica internacional (UNIVERSITÉ, 2012).

O Plateau Saclay, que deu origem ao projeto, transformou-se no primeiro polo cientifico de ciências da indústria depois da Segunda Guerra Mundial. O CNRS e o CEA se instalaram nessa região, seguidos, nos anos 1970, pela Escola Politécnica e Supelec, e mais recentemente pelo centro de pesquisa e desenvolvimento da Danone e dos laboratórios de Thales. Ele produz $10 \%$ da pesquisa na França 
e conta com 2 prêmios Nobel e 6 medalhas Fields. O polo recebeu o Label Idex "Iniciativa de Excelência" em fevereiro de 2012, que prevê a criação da Universidade Paris-Saclay, contando com a participação de duas universidades, dez grandes escolas, sete organismos de pesquisa e estimando receber 50.000 estudantes, posicionando-se entre os 10 melhores estabelecimentos de ensino e pesquisa na classificação de Xangai (UNIVERSITÉ, 2012).

\subsection{A conferência de presidentes de universidades}

AConferência de Presidentes (reitores, no Brasil) de Universidades (CPU), redefinida na lei Liberdades e Responsabilidades das Universidades (LRU), de 10 de agosto de 2007, é uma associação sem fins lucrativos e de utilidade pública. Ela representa os interesses comuns dos estabelecimentos que reúne. Atualmente, a CPU congrega 77 universidades, três universidades tecnológicas, duas instituições nacionais politécnicas, três escolas normais superiores, dois institutos nacionais de ciências aplicadas, uma escola central, quatro escolas francesas no exterior, quinze grandes estabelecimentos e dezoito polos de pesquisa e ensino superior (PRES).

Foi criada em 1971 como um espaço de intercâmbio de ideias, de reflexão e de acompanhamento das grandes mudanças pelas quais passavam as universidades francesas. Com o tempo, tornou-se uma interlocutora incontornável dos poderes públicos sobre a questão universitária.

A CPU tem como vocação a promoção da universidade na França e no mundo, consciente das dificuldades que encontra a sociedade civil para compreender o sistema de ensino superior francês. Ela pode agir como um agente importante para a visibilidade da comunidade universitária. Adimensão internacional é uma das grandes preocupações, sobretudo dentro do espaço europeu de ensino superior e pesquisa. Em 1997, a CPU criou uma delegação permanente em Bruxelas junto a outros organismos de pesquisa, como o CNRS, INSERM, CEA, INR, entre outros, dentro do CLORA (Clube de Ligação dos Organismos de Pesquisa) (FRANCE, CPU, on-line). 
A LRU define como membros de direito da CPU os presidentes e diretores das universidades, das escolas normais superiores e dos grandes estabelecimentos.

\subsection{AERES - Agência de Avaliação da Pesquisa e do Ensino Superior}

A Agência de Avaliação da Pesquisa e do Ensino Superior (AERES) é uma autoridade administrativa independente criada pela Lei de Programa de Pesquisa de 2006, operacional a partir de 2007. Ela engloba o conjunto de estabelecimentos de ensino superior e pesquisa na França, assim como os laboratórios de pesquisa. As avaliações são feitas por comissões compostas por especialistas franceses e estrangeiros escolhidos pela AERES a partir de uma proposta da comunidade cientifica. A avaliação é feita por um comitê de especialistas a partir do estudo de um dossiê composto de uma autoavaliação e de uma visita da estrutura avaliada. A avaliação dos masters e licences é feita a partir de um dossiê estudado pelo comitê de especialistas reunidos na Agência.

A AERES publicou, em janeiro de 2011, a primeira avaliação cartográfica do ensino superior e da pesquisa na França, por Academia, entre 2007 e 2010. Em menos de quatro anos, 10.000 avaliações foram feitas, contando com o trabalho de 4.500 especialistas. Segundo JeanFrançois Dhainaut, a AERES criou uma dinâmica na busca da qualidade e do progresso. A primeira avaliação cartográfica é um instrumento inovador e indispensável, o qual estima que é necessário promover a autoavaliação e a avaliação internacional. Desse estudo, vale a pena citar alguns pontos da análise feita pelo presidente da Agência, JeanFrançois Dhainaut (FRANCE, AERES, on-line):

- Existe uma relação forte entre a qualidade da pesquisa e a qualidade dos Masters.

- Nota-se uma estreita colaboração que tornou-se efetiva ao longo dos últimos anos entre as universidades e as grandes escolas, entre as universidades e os organismos de pesquisa, entre as universidades e os hospitais 
universitários ( $\mathrm{CHU})$, entre os atores do ensino superior e da pesquisa e o mundo socioeconômico.

- As grandes metrópoles lançaram uma reflexão sobre os projetos colaborativos permitindo a implantação de grandes conjuntos técnico-científicos,

- Fora das grandes metrópoles as colaborações estreitas são indispensáveis para se alcançar uma massa crítica, o que permitira as regiões de trabalhar nas mesmas condições que as metrópoles,

- As universidades mais jovens atingem dificilmente os objetivos de pesquisa, o que poderia ser feito eventualmente em colaboração com as grandes metrópoles.

\section{Conclusão}

A França sofreu um sobressalto importante quando, em 2003, foi publicada a classificação internacional das universidades por Xangai, na qual sequer dez universidades francesas faziam parte da lista das cem primeiras melhores universidades do mundo. $O$ choque foi tremendo e as reformas que já estavam em curso se tornaram prementes. Atualmente, o sistema francês de ensino superior está integrado ao Processo de Bolonha, dito LMD, facilitando, com o sistema de aproveitamento de créditos ECTS, a mobilidade dos estudantes europeus. Esse sistema integrado permite uma grande mobilidade dos jovens franceses $e$, consequentemente, maior permeabilidade de todo o tecido social às novidades existentes nos países membros.

A França também vive um momento difícil com a autonomia dada às universidades, pois se tem a impressão de que só as maiores e mais vigorosas poderão continuar existindo, enquanto as outras, menores e mais frágeis, desaparecerão ou serão "engolidas", formando assim, os grandes polos de ensino e pesquisa. As reformas pelas quais passa o sistema francês de ensino são necessárias para que o país possa concorrer com as melhores universidades dentro de um sistema de globalização impiedoso, no qual aqueles que não se adaptam e não procuram melhorar seu sistema estão fadados à mediocridade. 
Xangai serviu de aviso e a França soube reagir, começando uma reforma de seu sistema de maneira difícil, enfrentando os movimentos sociais e a força da inércia. Foram criados os polos de pesquisa e ensino superior (PRES), assim como grandes polos de pesquisa integrados em um território, como é o caso do Plateau Saclay.

A atual crise que a Europa enfrenta não serve de alento aos jovens que estudam e não encontram emprego na saída das universidades. Mesmo enfrentando tantas dificuldades, a França continua tendo renomados laboratórios de pesquisa e um sistema de ensino que soube se avaliar e se reformar. Seu futuro e sua afirmação como potência mundial dependerá de sua capacidade para enfrentar os desafios de um mundo globalizado, da atração de cérebros, do poder de iniciativa criativa e de uma organização racional de seus recursos humanos e financeiros.

O comitê que segue a aplicação da lei de 10 de agosto de 2007 sobre as liberdades e responsabilidades das universidades publicou seu $4^{\circ}$ relatório anual em janeiro de 2012 . A lei prevê que no dia $1^{\circ} \mathrm{de}$ janeiro de 2013 as universidades administrem de maneira autônoma seu orçamento e seus funcionários. Em janeiro de 2012, todas as universidades da metrópole francesa adquiriram essa autonomia. Considera-se que a reforma prevista pela lei só poderá ter sucesso se os recursos atribuídos às universidades forem suficientes e o Estado evoluir paralelamente com as novas capacidades de iniciativa das universidades francesas.

\section{Referências}

BRASIL. Campus France e embaixada da França no Brasil. Disponível em: <http://riodejaneiro.ambafrance-br.org/Campusfrance,366>. Acesso em: 16 set.2012.

BALME, P. et al. L'Université française: une nouvelle autonomie, un nouveau management. Grenoble: Presses Universitaires de Grenoble, 2012. 
CHABBAL, Robert; GOULARD, François. L'enseignement supérieur en France, état des lieux et propositions. Paris, 2007. Disponível em: <http://www.ladocumentationfrancaise.fr/rapports-publics/074000710/ index.shtml>. Acesso em: 3 set. 2012.

CYTERMANN, Jean-Richard. Les spécificités du financement de l'éducation en France- Existe-t-il un modèle éducatif français? Revue de l'inspection générale, Paris, n. 3, p. 101- 107, 2006.

ENSEIGNANTS: vocation en berne. Le Monde, Paris, p. 14-15, 9 jun. 2011.

L'EUROPE parie sur la diplomatie scientifique. Les Echos, Paris, p. 10, 17 set. 2012.

FRANCE. Agence d'Évaluation de la Recherche et del'Enseignement Supérieur. Disponível em: <http://www.aeres-evaluation.fr>. Acesso em: 10 out. 2012.

FRANCE. Conférence des présidents d'Universités. Disponível em: <http://www.cpu.fr>. Acesso em: 16 set. 2012.

FRANCE. Loi $\mathbf{n}^{\circ}$ 2007-1199, de 10 de agosto de 2007. Dispõe sobre as liberdades e responsabilidades das universidades. Paris. Disponível em: $\quad<$ http://www.legifrance.gouv.fr/affichTexte.do?cidTexte=JORFTE XT000000824315>. Acesso em: 15 nov. 2012.

FRANCE. Ministère de l'enseignement supérieur et de la recherche. Disponível em: <http://www.enseignementsup-recherche.gouv.fr> Acesso em: 15 nov. 2012.

FRANCE. Decreto 2007-1001 de 31 de maio de 2007 relativo às atribuições do Ministro do Ensino Superior e da Pesquisa. Disponível em: <http://www.enseignementsup-recherche.gouv.fr>. Acesso em: 15 de novembro de 2012.

FRANCE. Decreto 2000-298 de 6 de abril de 2000 relativo as atribuições do Ministro da Educação Nacional. Disponível em: <www.education.gouv.fr>. Acesso em: 30 nov. 2012.

LEFEBVRE, Olivier. L'état de l'enseignement supérieur et de la recherche en France. Paris, 2010. Disponível em: <http://www. enseignementsup-recherche.gouv.fr>. Acesso em: 5 out. 2012. 
PARFAIRE. Les établissements d'enseignement supérieur, structure et fonctionnement. France 2009. Disponível em: <http:// www.parfaire.fr/index.php>. Acesso em: 5 out. 2012.

PLAN Campus: le Gouvernement s'interroge. Le Figaro, Paris, p. 22, 27 maio 2012.

QUE VALENT encore nos Universités? Les Echos, Paris, p 58-75,10 abr. 2006.

QUERE, Michel. Repères et références statistiques sur les enseignements, la formation et la recherche. France, 2011. Disponível em: <http://media.education.gouv.fr/file/2011/01/4/DEPPRERS-2011_190014.pdf>. Acesso em: 15 nov. 2012

SEVE, René. L'investissement dans l'enseignement supérieur en France doit-il augmenter?Center d'Analyse Stratégique, Paris, n. 142, p. 1-10, 2009.

UNIVERSITÉ: le projet Paris-Saclay s'enlise. Le Figaro, Paris, p. 10, 13 set. 2012.

VALENTIN, Thierry. Guide de la cooperation universitaire Francobresilienne. Paris: CampusFrace/Cendotec, 2009.

Recebido em: 07/11/12

Aprovado em: 28/12/12 